\title{
Clinical scoring in gestational diabetes screening
}

\author{
V. Seshiah
}

Received: 8 May 2012 / Accepted: 18 May 2012 / Published online: 19 June 2012

(C) Research Society for Study of Diabetes in India 2012

Women with a history of GDM are at increased risk of future diabetes, predominantly type 2 diabetes, as are their children [1]. Additionally other compelling reasons for addressing GDM include the elevated risk of adverse pregnancy outcomes, including increased maternal and perinatal morbidity, obstructed labor, infections, spontaneous abortion, congenital abnormalities and macrosomia. Women with GDM have an increased lifetime risk of developing diabetes, which is more than 3 times that of control population at 16 years after index pregnancy [2]. By 17 years of age one-third of children born to GDM mothers have had evidence of IGT or Type 2 DM [3]. Furthermore, women with a history of GDM are also at increased risk of future cardiovascular disease and thus, screening for GDM has become imperative.

Screening test for GDM should identify subjects at risk either using clinical risk factors or by biochemical testing. Traditional risk factors have not included ethnic origin, and are relatively insensitive (less than $70 \%$ ) when applied to multiethnic antenatal clinics, as women from ethnic minorities are at substantial greater risk of GDM than Caucasian women [4].

ADA expert committee recommended a strategy for potential "exclusion from blood glucose testing" on the basis of below average risk for GDM rather than testing only on the basis of category of high risk like obesity, strong family history of type $2 \mathrm{DM}$, previous history of GDM or glucose intolerance outside of pregnancy and glucosuria and history of poor obstetrics outcome [5]. But selective screening

\section{Seshiah $(\varangle)$}

Dr V Seshiah Diabetes Research Institute and Dr Balaji Diabetes

Care Centre,

Chennai 600 029, India

e-mail:vseshiah@gmail.com based on risk factor scored poorly in predicting GDM [6]. If selective screening is employed it is likely that $27 \%$ of the GDM women will go undetected [6]. GDM diagnosis is overlooked in about one-third of the women where selective rather than universal screening is performed [7]. Further selective screening recommendation by American Diabetes Association (ADA) may be applicable for women belonging to the ethnic group with low prevalence of GDM. Risk factor screening does not take into account the inevitable difficulties in implementation including the potential for substantial under diagnosis of GDM [8].

Compared to risk factor based selective screening, universal screening for diabetes detects more cases and improves maternal and offspring prognosis [9]. Thus, universal screening appears to be the most reliable and desirable method for the detection of GDM [6]. In this aspect, diagnosis of GDM by WHO criteria is cost effective. GDM is diagnosed if $2 \mathrm{~h}$ Plasma Glucose $(\mathrm{PG}) \geq 140 \mathrm{mg} / \mathrm{dl}$ ( $7.8 \mathrm{mmol} / \mathrm{L})$, with $75 \mathrm{~g}$ OGTT similar to that of Impaired Glucose Tolerance (IGT) outside Pregnancy [10]. WHO criteria of $2 \mathrm{~h} \mathrm{PG}$ more than $140 \mathrm{mg} / \mathrm{dl}$ identifying large number of cases may have greater potential for prevention [11]. But the WHO criteria require women to be in the fasting state. Hence, a procedure that does not require any restriction would be ideal for universal screening. It is important to have a test that detects glucose tolerance without the women necessarily undergoing a test in the fasting state as pregnant women seldom visit an antenatal clinic in the fasting state. The test results should be informative from the blood collected from pregnant women irrespective of their last meal timing. Collecting the blood sample for the measurement of glucose concentration without regard to the time of the day or the interval since the last food intake (random sampling) has also been advocated as a simpler and adequate method for blood sugar screening [12]. A single 
sample drawn $2 \mathrm{~h}$ after $75 \mathrm{~g}$ glucose load approaches the standard glucose challenge test (GCT) in simplicity [12]. Yet another study suggests a similar procedure in that, a pregnant woman after undergoing preliminary clinical examination in the prenatal clinic is given a $75 \mathrm{~g}$ oral glucose load, without regard to the time of the last meal and venous blood sample is collected at $2 \mathrm{~h}$ for estimating PG by the GOD-POD method. GDM is diagnosed, if $2 \mathrm{~h} \mathrm{PG}$ is $>$ $140 \mathrm{mg} / \mathrm{dL}$ [13]. Performing this test procedure in the nonfasting state is rational, as glucose concentrations are affected little by the time since the last meal in a normal glucose tolerant woman, whereas it will, in a woman with GDM [14]. After a meal, a normal glucose tolerant woman would be able to maintain euglycemia despite glucose challenge due to brisk and adequate insulin response, whereas in case of a woman with GDM who has impaired insulin secretion [15] glycemic level increases with a meal and the glycemic excursion exaggerates with glucose challenge further. Therefore, this procedure assumes clinical relevance as WHO criteria based on glucose concentration $2 \mathrm{~h}$ after $75 \mathrm{~g}$ glucose load was able to correctly identify subjects with GDM. This single step procedure serves as both screening and diagnostic test for GDM, and is simple, economical and feasible [13]. The $2 \mathrm{~h} \mathrm{PG}>140 \mathrm{mg} / \mathrm{dl}$ has got clinical significance as both short term and long term morbidity in the offspring of GDM mothers occurs above this glycemic level [16].

International Association of Diabetes and Pregnancy Study Groups (IADPSG) recommendations suggest that GDM can be diagnosed if $\mathrm{FPG}>92 \mathrm{mg} / \mathrm{dl}$. Thus, estimation of FPG is also an option but has limitations in South Asians and Asian Indian population. This is due to the ethnicity of Asian Indians who have high Insulin Resistance (IR) and as a consequence, their postprandial plasma glucose is higher compared to Caucasians [17]. Asian and South Asian ethnicity are both independently associated with increased IR in late pregnancy [18]. Das et al. documented an increased IR during pregnancy in Asian Indian Women and the IR escalates further in GDM [19]. All these studies indicate that FPG is inadequate to diagnose GDM.

Clinical risk factors were poor predictors of GDM. A possible reason could be that the South Asians are generally at higher risk for GDM and thus more prone to developing it than Caucasians [20]. Important highlight is the need for universal screening in high risk population. Risk factor based screening would miss $10-40 \%$ of women with GDM [21, 22].

Cost analysis of universal screening when compared with risk factor screening showed only negligible difference [6]. For Universal screening, estimating the plasma glucose is the most reliable and desired method. In this regard, the cost effective and evidence based single step procedure serves as a both definitive screening and diagnostic test procedure [13].

\section{References}

1. Dornhost A, Rossi M. Risk and prevention of Type 2 Diabetes in women with gestational diabetes. Diabetes Care. 1998;21(Suppl2):B43-9.

2. Henry OA, Beischer NA. Long-term implications of gestational diabetes for the mother. Baillieres Clin obstet Gynaecol. 1991;5:461-83.

3. Silvermen BL, Cho NH, et al. Long-term effects of the intrauterine environment. Diabetes Care. 1998;21:B142.

4. Dornhost A, Paterson CM, Nicholls JS et al. High prevalence of GDM in women from ethnic minority groups. Diabetic Med. 1992;9:820-2.

5. Marquette GP, Klein VR, Niebyl JR. Efficacy of screening for gestational diabetes. Am J Perinatol. 1985;2:7-9.

6. Shamsuddin K, Mahdy ZA, Siti Rafiaah I et al. Risk factor screening for abnormal glucose tolerance in pregnancy. Int $\mathrm{J}$ Gynecol Obstet. 2001;75:27-32.

7. Cosson E, Benthimol M, Carbilon L et al. Universal screening for gestational diabetes mellitus improves maternal and fetal outcomes compared with selective screening. In : Mateclinsky FM (ed). Abstract book of the 64th Scientific Sessions of the American Diabetes Association (ADA). Florida. American Diabetes Association 2004; A61.

8. Simmons D, Devers MC, Wolmarans L et al. Difficulties in the use of risk factors to screen for gestational diabetes mellitus. Diabetes Care. 2009;32:e8.

9. Cosson E. Screening and insulin sensitivity in gestational diabetes. Abstract volume of the $40^{\text {th }}$ Annual Meeting of the European Association for the Study of Diabetes, September 2004: A 350.

10. Alberti K, Zimmett P. Definition, diagnosis and classification of diabetes mellitus and its complications, Part 1: diagnosis and classification of diabetes mellitus provisional report of a WHO consultation. Diabet Med. 1998;15:539-53.

11. Schmidt MI, Duncan BB, Reichelt AJ et al. Gestational diabetes mellitus diagnosed with a 2-h 75-g oral glucose tolerance test and adverse pregnancy outcomes. Diabetes Care. 2001;24:1151-5.

12. Pettitt DJ, Knowler WC, Baird R, Bennett PH. Gestational diabetes: infant and maternal complications of pregnancy in relation to third-trimester glucose tolerance in the Pima Indians. Diabetes Care. 1980;3:458-64.

13. Anjalakshi C, Balaji V, Balaji MS et al. A single test procedure to diagnose gestational diabetes mellitus. Acta Diabetol. 2009;46:51-4.

14. Gough WW, Shack MJ, Bennett PH, Burch TA, Miller M. Evaluation of glucose in the Pima Indians by longitudinal studies. Diabetes. 1970;19 Suppl 1:388.

15. Kuhl C, Hornnes PJ, Andersen O. Etiology and pathophysiology of gestational diabetes mellitus. Diabetes. 1985;34 Suppl 2:66-70.

16. Crowther CA, Hiller JE, Moss JR et al. Effect of treatment of gestational diabetes mellitus. N Engl J Med. 2005;352:2477-86.

17. Mohan V, Sandeep S, Deepa R, Shah B, Varghese C. Epidemiology of Type 2 diabetes: Indian Scenario. Indian J Med Res. 2007;125:217-30.

18. Retnakaran R, Hanley AJ, Connelly PW, Sermer M, Zinman B. Ethnicity modifies the effect of obesity on insulin resistance in pregnancy: a comparison of Asian, South Asian and Caucasian women. J Clin Endocrinol Metab. 2006;91:93-7.

19. Das S, Behera MK, Misra S, Baliarsihna AK. B-cell function and insulin resistance in pregnancy and their relation to fetal development. Metab Syndr Relat disorder. 2010;8:25-32.

20. Ferrara A. Increasing prevalence of gestational diabetes mellitus: a public health perspective. Diabetes Care. 2007;30 Suppl 2:S141-6.

21. Tan PC, Ling LP, Omar SZ. Screening for gestational diabetes at antenatal booking in a Malaysian university hospital: The role of risk factors and threshold value for the $50 \mathrm{~g}$ glucose challenge test. Aust N Z J Obstet Gynecol. 2007;3:191-7.

22. Balaji V, Balaji M, Anjalakshi C, et al. Diagnosis of gestational diabetes mellitus in Asian-Indian women. Indian J Endocrinol Metab. 2011;15:187-90. 